\title{
Associated bone mineral density and obstructive sleep apnea in chronic obstructive pulmonary disease
}

\author{
Tsai-Yu Wang' \\ Yu-Lun Lo ${ }^{1,2}$ \\ Pai-Chien Chou' \\ Fu-Tsai Chung' \\ Shu-Min Lin' \\ Ting-Yu Lin' \\ Horng-Chyuan Lin' \\ Chun-Hua Wang' \\ Chih-Teng Yu' \\ Han-Pin Kuo' \\ 'Department of Thoracic Medicine, \\ School of Medicine, Chang Gung \\ Memorial Hospital and Chang Gung \\ University, Taipei, Taiwan; ${ }^{2}$ Healthcare \\ Center, Chang Gung Memorial \\ Hospital, Taipei, Taiwan
}

This article was published in the following Dove Press journal: International Journal of COPD

29 January 2015

Number of times this article has been viewed

Background: Osteoporosis is an important issue for patients with chronic obstructive pulmonary disease (COPD). Worse systemic inflammation and reduced exercise capacity have been reported in COPD patients with obstructive sleep apnea (OSA), implying that OSA may be an independent factor for osteoporosis in COPD patients.

Methods: A total of 66 patients with bone mineral density (BMD) and polysomnography results from a previous COPD cohort (January 2008 to January 2013) were retrospectively enrolled. Clinical characteristics such as medication, pulmonary function, BMD, and results of polysomnography were analyzed.

Results: The BMD in those with OSA was significantly lower than in those without OSA $(-1.99 \pm 1.63$ versus $-1.27 \pm 1.14, P=0.045)$. In univariate analysis, body mass index, forced expiratory volume in 1 second, percentage of predicted value, incremental shuttle walk test, apnea-hypopnea index, and oxygen desaturation index (ODI) were significantly associated with BMD. After multivariate linear regression analysis, the ODI was still an independent factor for BMD. In addition, smaller total lung capacity is significantly associated with higher ODI and lower BMD, which implies that lower BMD might cause severer OSA via decreased total lung capacity.

Conclusion: OSA may be an independent factor for BMD in patients with COPD, which implies a possible vicious cycle takes place in these patients.

Keywords: chronic obstructive pulmonary disease, osteoporosis, total lung capacity

\section{Introduction}

Chronic obstructive pulmonary disease (COPD) is a serious health burden and a major cause of mortality worldwide. ${ }^{1}$ Aside from the progressive loss of pulmonary function, extra-pulmonary comorbidities such as low skeletal muscle mass, cardiovascular disease, pulmonary hypertension, obstructive sleep apnea (OSA), and osteoporosis play an important role in the mortality of COPD patients. ${ }^{1-4}$

Osteoporosis, characterized by a decrease in bone mineral density (BMD), is reported to affect $9 \%-69 \%$ of patients with $\mathrm{COPD},{ }^{5}$ indicating that COPD patients have a high risk of developing osteoporosis. The etiology of osteoporosis in COPD patients is complex and variable, and includes chronic systemic inflammation (TNF- $\alpha$ promoting bone loss), ${ }^{6}$ therapy (corticosteroid treatment), and natural changes because of aging, physical deconditioning (low skeletal muscle mass). ${ }^{7}$

With regard to physical activity, a recent study revealed that walking capacity is impaired when COPD patients have OSA, also called the overlap syndrome. In addition, this impairment can be partially reversed by continuous positive airway pressure
Department of Thoracic Medicin Chang Gung Memorial Hospital, 199 Tun-Hwa North Road, Taipei, Taiwan

Tel $+8863328 \quad 1200$ ext 8467

Fax +88633282474

Email q8828@ms I I.hinet.net 
(CPAP) treatment, ${ }^{8}$ implying that OSA is a possible cause for the low level of physical activity in COPD patients. Moreover, a low level of physical activity may lead to negative effects in patients with osteoporosis. ${ }^{9}$ Furthermore, OSA patients have been reported to have a higher avidity and cytotoxicity of $\gamma \delta$ T-cells, which are mainly attributed to the proinflammatory cytokine TNF- $\alpha .{ }^{10}$ TNF- $\alpha$ promotes further bone loss, ${ }^{6}$ which may further contribute to osteoporosis. Therefore, OSA may be a possible etiology responsible for osteoporosis in COPD patients, a finding that has not previously been reported. The primary aim of this study was to evaluate the BMD between COPD patients with and without OSA. The secondary aim was to evaluate the association between BMD and severity of OSA.

\section{Materials and methods Study population}

We retrospectively recruited patients with COPD from January 2008 to January 2013 in Chang Gung Memorial Hospital, a tertiary hospital in Taiwan. Patients were excluded if data of BMD and polysomnography were not available or if the patients had any history of malignancy. Those COPD patients would be referred to sleep laboratory while they had snoring. Therefore, data of polysomnography were not available if those COPD patients had no snoring history. The Chang Gung Medical Foundation Institutional Review Board approved this study (102-3093B) and waived the requirement for informed consent due to the retrospective nature of the study.

\section{Study design}

The medical records of each patient were reviewed to collect the clinical characteristics and laboratory results. In addition, data on BMD, polysomnography, pulmonary function, incremental shuttle walk test (ISWT), and medication were analyzed.

\section{Definitions}

COPD was defined as forced expiratory volume in 1 second/forced vital capacity $\left(\mathrm{FEV}_{1} / \mathrm{FVC}\right)$ ratio less than $70 \%$ and an increase in forced expiratory volume in 1 second less than $12 \%$ of baseline after inhalation of $\beta_{2}$ agonist. ${ }^{1}$ Based on the polysomnography results, OSA was defined as an apnea-hypopnea index (AHI) $>15$ per hour, of which $\geq 50 \%$ were obstructive. Sleep stages and arousals were scored according to the AASM criteria. ${ }^{11}$ Established criteria were used to score respiratory events such as hypopnea, obstructive apnea, central apnea, mixed-type apnea, and Cheyne-Stokes respiration. ${ }^{12,13}$ Apnea was defined as oronasal flow cessation for more than 10 seconds. Hypopnea was defined as a 50\% reduction in oronasal flow for more than 10 seconds; or a $30 \%$ reduction followed, by arousal or more than $3 \%$ decrease in oxygen saturation. ${ }^{12}$ The BMD was determined by dualenergy X-ray absorptiometry. The BMD was expressed as a T-score (standard deviations from a young, sex-specific reference mean BMD). ${ }^{14}$ ISWT was performed as in a previous study. ${ }^{15}$

\section{Statistical analysis}

Data were expressed as mean \pm standard deviation or mean \pm standard error of the mean. The Student's $t$-test was used for comparisons of continuous variables between those with and without OSA, while the Mann-Whitney test was used for non-normal distributions. Categorical variables were compared by chi-square or Fisher's exact tests. The Pearson product correlation coefficient was used to examine correlations between variables and the BMD. Multivariate linear regression analysis was used to determine the independent factors associated with the BMD. A $P$-value less than 0.05 was considered to be statistically significant. All analyses were performed using the SPSS software package version 13.0 (SPSS Inc., Chicago, IL, USA).

\section{Results}

\section{Demographic and clinical} characteristics of the patients

A total of 312 patients with COPD were identified between January 2008 and January 2013, 30 of whom were excluded due to the following reasons: $194(62.2 \%)$ did not have polysomnography data; 45 (14.4\%) had malignancy; and seven $(2.2 \%)$ did not have data on dual-energy X-ray absorptiometry for BMD. The records of the remaining 66 patients were further reviewed, of whom 35 had OSA and 31 did not. The baseline demographic data and clinical characteristics of these patients are listed in Table 1. The mean ages of the COPD patients with and without OSA were similar (71.5 and 71.6 years, respectively). The BMD in those with OSA was significantly lower than that in those without OSA $(-1.99 \pm 1.63$ versus $-1.27 \pm 1.14, P=0.045)$. Other characteristics including smoking, pulmonary function, and medications (including inhaled corticosteroids, long-acting $\beta_{2}$ agonists, long-acting muscarinic antagonists, 
Table I Patients characteristics

\begin{tabular}{|c|c|c|c|}
\hline Characteristics & $\begin{array}{l}\text { COPD without } \\
\text { OSA }(n=31)\end{array}$ & $\begin{array}{l}\text { COPD with } \\
\text { OSA }(n=35)\end{array}$ & $P$-value \\
\hline Age & $71.6 \pm 8.5$ & $71.5 \pm 8.6$ & 0.951 \\
\hline Male, n (\%) & $29(93.5)$ & $33(94.3)$ & 0.348 \\
\hline BMI & $23.8 \pm 3.4$ & $24.9 \pm 4.3$ & 0.958 \\
\hline Smoke, PKY & $50.5 \pm 28.9$ & $51.7 \pm 22.3$ & 0.850 \\
\hline \multicolumn{4}{|l|}{ Pulmonary function test } \\
\hline $\mathrm{FEV}_{1} / \mathrm{FVC}$ & $55.5 \pm 9.4$ & $54.4 \pm 10.4$ & 0.651 \\
\hline $\mathrm{FEV}_{1}$ (\% predicted) & $46.8 \pm 15.9$ & $46.4 \pm 23.0$ & 0.927 \\
\hline FVC (\% predicted) & $60.2 \pm 15.7$ & $61.1 \pm 23.9$ & 0.850 \\
\hline $\begin{array}{l}\text { Incremental shuttle } \\
\text { walk test, } \mathrm{m} \\
\text { BMD }\end{array}$ & $279.7 \pm 107.2$ & $240.9 \pm 88.4$ & 0.168 \\
\hline $\begin{array}{l}\text { T-score (lumbar } \\
\text { spine L2-4) }\end{array}$ & $-1.27 \pm 1.14$ & $-1.99 \pm 1.63$ & 0.045 \\
\hline \multicolumn{4}{|l|}{ Medication } \\
\hline LABA, n (\%) & $29(93.5)$ & $32(91.4)$ & 0.999 \\
\hline ICS, n (\%) & $29(93.5)$ & $32(91.4)$ & 0.999 \\
\hline LAMA, n (\%) & $24(77.4)$ & $31(88.6)$ & 0.324 \\
\hline Theophyllines, n (\%) & $7(22.6)$ & $12(34.3)$ & 0.415 \\
\hline $\begin{array}{l}\text { Oral } \\
\text { corticosteroids, n (\%) }\end{array}$ & II (35.5) & $7(20)$ & 0.178 \\
\hline PPI, n (\%) & II (35.5) & $17(48.6)$ & 0.326 \\
\hline
\end{tabular}

Note: Data are presented as mean \pm standard deviation, or number (percentage). Abbreviations: BMD, bone mineral density; BMI, body mass index; COPD, chronic obstructive pulmonary disease; $\mathrm{FEV}_{1}$, forced expiratory volume in I second; FVC, forced volume capacity; ICS, Inhaled corticosteroids; LABA, long-acting $\beta_{2}$ agonist; LAMA, long-acting muscarinic antagonist; OSA, obstructive sleep apnea; PKY, pack years; PPI, proton pump inhibitor.

theophylline, oral corticosteroids, and proton pump inhibitors) were similar between the two groups. With regards to the polysomnographic results (Table 2), the mean AHI in those with OSA was $37.0 \pm 16.7 / \mathrm{h}$ of sleep, indicating that most of the patients had severe OSA, accompanied by greater

Table 2 Polysomnographic results

\begin{tabular}{|c|c|c|c|}
\hline & $\begin{array}{l}\text { COPD without } \\
\text { OSA }(n=31)\end{array}$ & $\begin{array}{l}\text { COPD with } \\
\text { OSA }(n=35)\end{array}$ & $P$-value \\
\hline $\begin{array}{l}\text { Total sleep time } \\
\text { (minutes) }\end{array}$ & $277.4 \pm 71.8$ & $254.8 \pm 70.5$ & 0.206 \\
\hline Sleep efficiency (\%) & $67.8 \pm 13.5$ & $64.2 \pm 14.9$ & 0.316 \\
\hline $\mathrm{AHI}$ events per hour & $8.6 \pm 3.9$ & $37.0 \pm 16.7$ & $<0.001$ \\
\hline ODI events per hour & $4.4 \pm 3.6$ & $21.1 \pm 15.4$ & $<0.00$ I \\
\hline Average $\mathrm{SaO}_{2} \%$ & $93.7 \pm 2.2$ & $93.2 \pm 2.5$ & 0.363 \\
\hline Lowest $\mathrm{SaO}_{2} \%$ & $87.6 \pm 4.2$ & $80.7 \pm 8.5$ & $<0.00 \mathrm{I}$ \\
\hline Wake \% TST & $25.6 \pm 13.7$ & $28.5 \pm 13.4$ & 0.407 \\
\hline NI \% TST & $18.8 \pm 12.1$ & $20.5 \pm 9.9$ & 0.525 \\
\hline N2 $\%$ TST & $32.9 \pm 14.0$ & $36.5 \pm 12.1$ & 0.273 \\
\hline N3 \% TST & $10.8 \pm 11.0$ & $6.5 \pm 9.1$ & 0.091 \\
\hline REM \% TST & $11.7 \pm 6.8$ & $8.0 \pm 7.1$ & 0.032 \\
\hline
\end{tabular}

Note: Data are presented as mean \pm standard deviation.

Abbreviations: AHI, apnea-hypopnea index; COPD, chronic obstructive pulmonary disease; ODI, oxygen desaturation index; OSA, obstructive sleep apnea; REM, rapid eye movement; $\mathrm{SaO}_{2}$, oxygen saturation; TST, total sleep time. desaturation (lowest oxygen saturation $80.7 \%$ ) and less rapid eye movement stage ( $8 \%$ of total sleep time).

\section{Univariate and multivariate linear regression analysis for the variables associated with BMD}

In univariate analysis, body mass index (BMI), $\mathrm{FEV}_{1} \%$, ISWT, AHI, and oxygen desaturation index (ODI) (Figure 1) were significantly correlated with BMD at the lumbar spine (Table 3), while age and use of inhaled corticosteroids, oral corticosteroids, and proton pump inhibitors were not. The multivariate stepwise linear regression analysis was used to analyze the independent factors contributing to BMD (Table 4). The association between BMD and AHI is revealed in Figure 1. Although, BMI, FEV 1 \%, ISWT, AHI, and ODI were chosen to be analyzed in multivariate stepwise linear regression, only $\mathrm{BMI}, \mathrm{FEV}_{1} \%$, and ODI were independent factors for BMD.

\section{The association between total lung capacity, BMD, and ODI}

Figure 2 reveals an association between total lung capacity and ODI ( $P<0.01, R=0.327, \mathrm{~N}=66)$. In addition, an association between total lung capacity and BMD is shown in Figure 3. $(P=0.025, R=0.314, \mathrm{~N}=66)$

\section{Discussion}

The results of this study demonstrated that the BMD was worse in those with OSA than in those without OSA. In multivariate analysis, ODI was still significantly associated

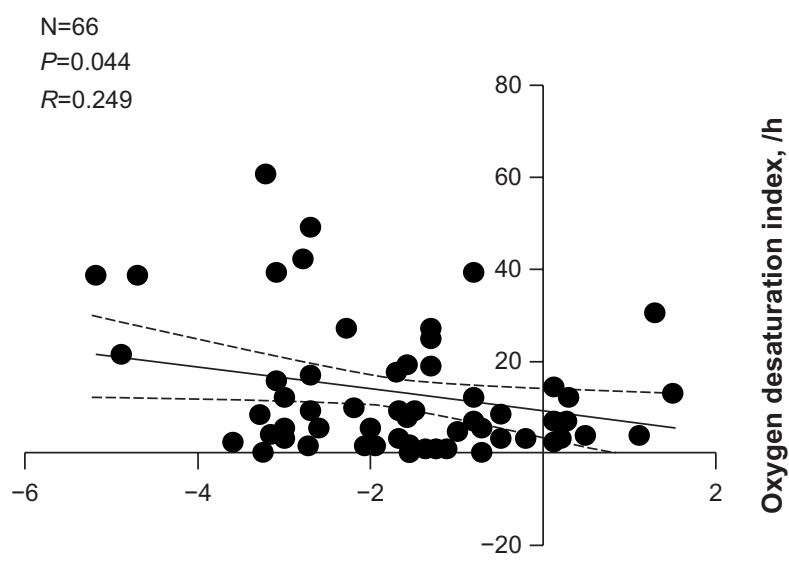

Bone mineral density, T-score

Figure I Correlation analysis: an association between bone mineral density and apnea-hypopnea index. 
Table 3 Univariate analysis of variables associated with BMD at lumbar spine

\begin{tabular}{lllll}
\hline Parameter & beta & $\begin{array}{l}\text { Standard } \\
\text { error }\end{array}$ & $\mathbf{9 5 \%} \mathbf{C I}$ & P-value \\
\hline Age & -0.013 & 0.02 I & -0.055 to 0.030 & 0.55 I \\
Sex & -0.290 & 0.76 I & -1.809 to 1.230 & 0.705 \\
BMI & 0.123 & 0.043 & 0.038 to 0.208 & 0.005 \\
FEV , \% & 0.025 & 0.009 & 0.008 to 0.043 & 0.005 \\
ISWT, m & 0.005 & 0.002 & 0.001 to 0.008 & 0.013 \\
AHI & -0.021 & 0.009 & -0.040 to -0.003 & 0.025 \\
ODI & -0.026 & 0.013 & -0.051 to -0.001 & 0.044 \\
ICS & 0.700 & 0.68 I & -0.661 to 2.061 & 0.308 \\
Oral & -0.668 & 0.399 & -1.466 to 0.130 & 0.099 \\
corticosteroids & & & & \\
PPI & -0.193 & 0.367 & -0.926 to -0.540 & 0.600 \\
\hline
\end{tabular}

Abbreviations: $\mathrm{AHI}$, apnea-hypopnea index; BMD, bone mineral density; BMI, body mass index; $\mathrm{Cl}$, confidence interval; $\mathrm{FEV}_{1}$, forced expiratory volume in I second; ICS, inhaled corticosteroids; ISWT, incremental shuttle walk test; ODI, oxygen desaturation index; PPI, proton pump inhibitor.

with BMD, which suggested that OSA played an important role in lower BMD in COPD patients. To the best of our knowledge, this finding has not previously been reported.

Osteoporosis is one of the systemic effects of COPD. ${ }^{1}$ Moreover, osteoporosis is associated with the COPD mortality. ${ }^{16}$ However, the detailed mechanism by which osteoporosis develops in COPD patients is still under debate. It is likely that the pathogenesis is multifactorial and includes age, progressive reduction of physical activity, low BMI, disease severity $\left(\mathrm{FEV}_{1} \%\right)$, systemic use of corticosteroids, and systemic inflammation. ${ }^{5,17}$ Age was not associated with BMD in this study, which may be due to the small age span of the study population. The BMI and $\mathrm{FEV}_{1} \%$ were significantly associated with osteoporosis, which was compatible with previous reports. ${ }^{5,18,19}$ Interestingly, ODI as a cardinal feature of OSA was also an independent contributing factor to BMD, which may be explained by two possible reasons. One is the systemic inflammation and another one is reduced physical activity. It is known that systemic inflammation is aggravated in patients with OSA, ${ }^{20}$ which is characterized by repetitive upper airway collapse and intermittent hypoxemia, and then it

Table 4 Multivariate linear regression: factors associated with BMD at lumbar spine

\begin{tabular}{lllll}
\hline Parameter & beta & $\begin{array}{l}\text { Standard } \\
\text { error }\end{array}$ & $\mathbf{9 5 \%} \mathbf{C l}$ & P-value \\
\hline BMI & 0.133 & 0.039 & 0.054 to $0.21 \mathrm{I}$ & 0.001 \\
FEV,$\%$ & 0.022 & 0.008 & 0.006 to 0.038 & 0.008 \\
ODI & -0.031 & 0.011 & -0.054 to -0.009 & 0.007 \\
\hline
\end{tabular}

Abbreviations: $\mathrm{BMD}$, bone mineral density; $\mathrm{BMI}$, body mass index; $\mathrm{Cl}$, confidence interval; $\mathrm{FEV}_{1}$, forced expiratory volume in I second; ODI, oxygen desaturation index.

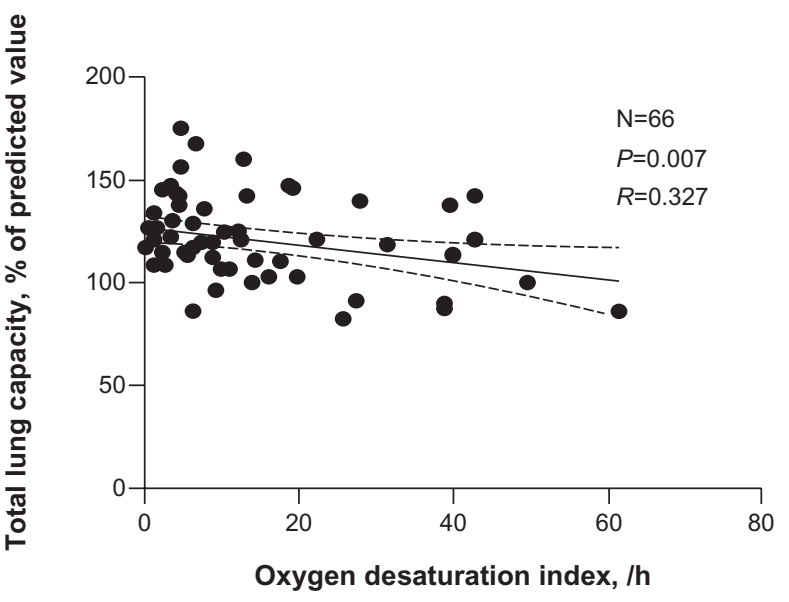

Figure 2 Correlation analysis: an association between total lung capacity and oxygen desaturation index.

may affect the activity of osteoblasts and osteoclasts. Another possible reason is the reduced level of physical activity in COPD patients with OSA. ${ }^{8}$

With regards to systemic inflammation, increased concentrations of circulating inflammatory mediators such as TNF- $\alpha$, IL-1, and IL-6 have been reported in COPD patients. ${ }^{21-23}$ Moreover, those oxidative stresses are associated with bone resorption during COPD exacerbation. ${ }^{24}$ TNF- $\alpha$ stimulates osteoblastic cells to express RANKL and M-CSF, which in turn prompt macrophages to become osteoclasts, leading to bone resorption. ${ }^{25-28}$ In addition, TNF- $\alpha$ and IL-1, via activation of osteoclast surface receptors, potentiate osteoclastogenesis and bone resorption. ${ }^{29}$ In addition, IL-6 is known to stimulate the formation of osteoclasts. ${ }^{29,30}$ OSA is accompanied by oxidative stress and inflammation via activation of NF-kB and downstream pathway. ${ }^{10}$ Moreover, some evidence also revealed that

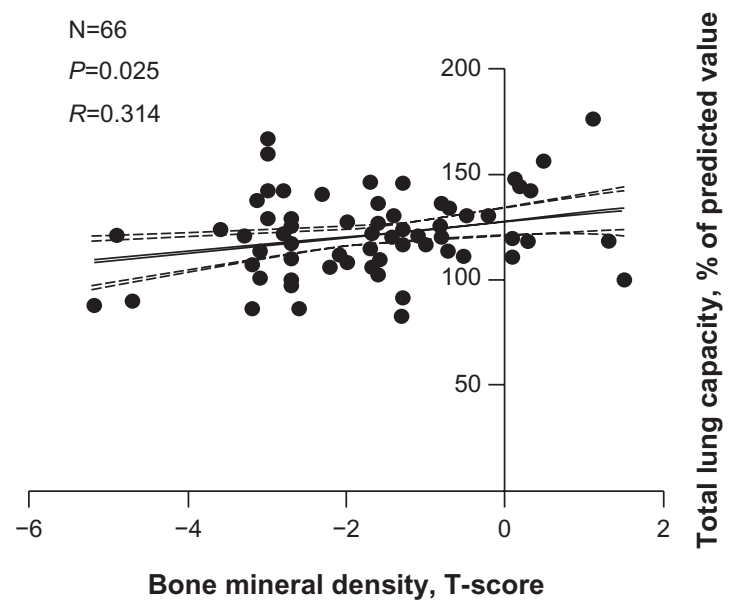

Figure 3 Correlation analysis: an association between total lung capacity and bone mineral density. 
TNF- $\alpha$, IL-1, and IL-6 are significantly elevated in patients with OSA. ${ }^{10,31,32}$ In addition, hypoxia also induces the formation of giant osteoclasts. ${ }^{33}$ Therefore, it is reasonable that the existence of OSA will lead to worsened BMD in COPD patients.

Physical activity is an important factor associated with osteoporosis. It has been reported to contribute to increased peak bone mass in youths, ${ }^{34,35}$ maintain bone mass in premenopausal women, and decrease loss of bone mass in postmenopausal women. ${ }^{36}$ The benefits of physical activity in the prevention of osteoporosis have been revealed. ${ }^{37,38}$ Interestingly, a pronounced reduction in exercise capacity in COPD patients was observed in a previous study. In COPD patients who have OSA, the exercise capacity will be worse, although this can be restored with CPAP treatment. ${ }^{8}$ Therefore, this reduced level of physical activity may be another possible reason for the worse BMD in COPD patients with OSA.

Increases in lung volume have been documented to dilate the pharynx and decrease its collapsibility, which suggests that increases in lung volume will ameliorate the severity of OSA. ${ }^{39-41}$ In addition, the lower BMD is associated with lower total lung capacity in the present study. Similarly, a recent study revealed that COPD patients with osteoporosis are associated with deteriorated pulmonary function. ${ }^{42}$ In addition, while COPD patients with osteoporosis received vertebroplasty for the osteoporotic vertebral compression fractures, the pulmonary function can be improved after this procedure. ${ }^{43}$ Decreases in lung volume in COPD patients with osteoporosis will deteriorate the severity of OSA. In addition, OSA will further deteriorate the osteoporosis in COPD patients. Therefore, while COPD patients have OSA, they will be in vicious cycle.

The major limitations of the present study are its retrospective nature, which may have led to bias in patient selection. Second, the sample size of the study is modest, and therefore the results of the study should be interpreted with caution. A prospective study with a larger sample size is warranted to further confirm the results. Physical activity has been reported as an independent factor associated with osteoporosis. However, ISWT was not an independent factor under multivariate analyses. The possible reason may be that ISWT is considered as a measurement of maximal exercise capacity, not a measurement of daily activity. ${ }^{44}$ Therefore, the 6-minute walk test may be used to confirm if daily physical activity is an independent factor for osteoporosis in COPD patients with OSA in the further study. Finally, the population in this study was based in a sleep lab, so extrapolation of the results to the general population should be done with caution.

\section{Conclusion}

In conclusion, the BMD of COPD patients with OSA was significantly worse than that of COPD patients without OSA. Moreover, ODI was still an independent factor associated with BMD in multivariate analysis. In addition, smaller total lung capacity is significantly associated with higher ODI and lower BMD, which implies that lower BMD might cause severer OSA via decreased total lung capacity. Therefore, OSA may be a contributory factor to BMD in patients with COPD.

\section{Acknowledgments}

The sponsor had no role in the design of the study, the collection and analysis of the data, or the preparation of the manuscript. This study was supported by a research grant from the Chang Gung Memorial Hospital (CMRPG3D0471). Dr Tsai-Yu Wang contributed to conceptualization and design of this study; collection, analysis, and interpretation of the data; and preparation of the manuscript. Dr Yu-Lun Lo contributed to conceptualization and design of this study, collection, analysis, interpretation of the data and preparation of the manuscript. Pai-Chien Chou, Fu-Tsai Chung, Shu-Min Lin, Ting-Yu Lin, Horng-Chyuan Lin, Chun-Hua Wang, and Chih-Teng Yu contributed to collection, analysis, and interpretation of the data and preparation of the manuscript. Dr Han-Pin Kuo contributed to conceptualization and design of the study; collection and interpretation of the data; and preparation of the manuscript.

\section{Disclosure}

The authors report no conflicts of interest in this work.

\section{References}

1. Rabe KF, Hurd S, Anzueto A, et al. Global strategy for the diagnosis, management, and prevention of chronic obstructive pulmonary disease: GOLD executive summary. Am J Respir Crit Care Med. 2007;176(6):532-555.

2. Marin JM, Soriano JB, Carrizo SJ, Boldova A, Celli BR. Outcomes in patients with chronic obstructive pulmonary disease and obstructive sleep apnea: the overlap syndrome. Am J Respir Crit Care Med. 2010;182(3):325-331.

3. Verbraecken J, McNicholas WT. Respiratory mechanics and ventilatory control in overlap syndrome and obesity hypoventilation. Respir Res. 2013;14:132

4. McNicholas WT, Verbraecken J, Marin JM. Sleep disorders in COPD: the forgotten dimension. Eur Respir Rev. 2013;22(129):365-375.

5. Graat-Verboom L, Wouters EF, Smeenk FW, van den Borne BE, Lunde R, Spruit MA. Current status of research on osteoporosis in COPD: a systematic review. Eur Respir J. 2009;34(1):209-218.

6. Gillespie MT. Impact of cytokines and T lymphocytes upon osteoclast differentiation and function. Arthritis Res Ther. 2007;9(2):103.

7. Baarends EM, Schols AM, Mostert R, Wouters EF. Peak exercise response in relation to tissue depletion in patients with chronic obstructive pulmonary disease. Eur Respir J. 1997;10(12):2807-2813. 
8. Wang TY, Lo YL, Lee KY, et al. Nocturnal CPAP improves walking capacity in COPD patients with obstructive sleep apnoea. Respir Res. 2013;14:66.

9. Pitta F, Troosters T, Spruit MA, Probst VS, Decramer M, Gosselink R. Characteristics of physical activities in daily life in chronic obstructive pulmonary disease. Am J Respir Crit Care Med. 2005;171(9):972-977.

10. Lavie L, Dyugovskaya L, Polyakov A. Biology of peripheral blood cells in obstructive sleep apnea - the tip of the iceberg. Arch Physiol Biochem. 2008;114(4):244-254.

11. No authors listed. EEG arousals: scoring rules and examples: a preliminary report from the Sleep Disorders Atlas Task Force of the American Sleep Disorders Association. Sleep. 1992;15(2): 173-184.

12. Berry RB, Budhiraja R, Gottlieb DJ, et al. Rules for scoring respiratory events in sleep: update of the 2007 AASM Manual for the Scoring of Sleep and Associated Events. Deliberations of the Sleep Apnea Definitions Task Force of the American Academy of Sleep Medicine. J Clin Sleep Med. 2012;8(5):597-619.

13. No authors listed. Sleep-related breathing disorders in adults: recommendations for syndrome definition and measurement techniques in clinical research. The Report of an American Academy of Sleep Medicine Task Force. Sleep. 1999;22(5):667-689.

14. No authors listed. Assessment of fracture risk and its application to screening for postmenopausal osteoporosis. Report of a WHO Study Group. World Health Organ Tech Rep Ser. 1994;843:1-129.

15. Liu WT, Wang CH, Lin HC, et al. Efficacy of a cell phone-based exercise programme for COPD. Eur Respir J. 2008;32(3):651-659.

16. Looker AC. Relationship between femur neck bone mineral density and prevalent chronic obstructive pulmonary disease (COPD) or COPD mortality in older non-Hispanic white adults from NHANES III. Osteoporos Int. 2014;25(3):1043-1052.

17. Romme EA, Murchison JT, Edwards LD, et al. CT-measured bone attenuation in patients with chronic obstructive pulmonary disease: relation to clinical features and outcomes. J Bone Miner Res. 2013;28(6):1369-1377.

18. McEvoy CE, Ensrud KE, Bender E, et al. Association between corticosteroid use and vertebral fractures in older men with chronic obstructive pulmonary disease. Am J Respir Crit Care Med. 1998; 157(3 Pt 1):704-709.

19. Ionescu AA, Schoon E. Osteoporosis in chronic obstructive pulmonary disease. Eur Respir J Suppl. 2003;46:64s-75s.

20. McNicholas WT. Chronic obstructive pulmonary disease and obstructive sleep apnea: overlaps in pathophysiology, systemic inflammation, and cardiovascular disease. Am J Respir Crit Care Med. 2009;180(8):692-700.

21. Eid AA, Ionescu AA, Nixon LS, et al. Inflammatory response and body composition in chronic obstructive pulmonary disease. Am J Respir Crit Care Med. 2001;164(8 Pt 1):1414-1418.

22. Bolton $\mathrm{CE}$, Broekhuizen R, Ionescu AA, et al. Cellular protein breakdown and systemic inflammation are unaffected by pulmonary rehabilitation in COPD. Thorax. 2007;62(2):109-114.

23. Schols AM, Buurman WA, Staal van den Brekel AJ, Dentener MA, Wouters EF. Evidence for a relation between metabolic derangements and increased levels of inflammatory mediators in a subgroup of patients with chronic obstructive pulmonary disease. Thorax. 1996;51(8):819-824.

24. Stanojkovic I, Kotur-Stevuljevic J, Spasic S, et al. Relationship between bone resorption, oxidative stress and inflammation in severe COPD exacerbation. Clinl Biochem. 2013;46(16-17):1678-1682.

25. Raisz LG. Local and systemic factors in the pathogenesis of osteoporosis. N Engl J Med. 1988;318(13):818-828.

26. Bertolini DR, Nedwin GE, Bringman TS, Smith DD, Mundy GR. Stimulation of bone resorption and inhibition of bone formation in vitro by human tumour necrosis factors. Nature. 1986;319(6053): $516-518$.
27. Hofbauer LC, Lacey DL, Dunstan CR, Spelsberg TC, Riggs BL, Khosla S. Interleukin-1beta and tumor necrosis factor-alpha, but not interleukin-6, stimulate osteoprotegerin ligand gene expression in human osteoblastic cells. Bone. 1999;25(3):255-259.

28. Kimble RB, Srivastava S, Ross FP, Matayoshi A, Pacifici R. Estrogen deficiency increases the ability of stromal cells to support murine osteoclastogenesis via an interleukin-1 and tumor necrosis factor-mediated stimulation of macrophage colony-stimulating factor production. $J$ Biol Chem. 1996;271(46):28890-28897.

29. Boyle WJ, Simonet WS, Lacey DL. Osteoclast differentiation and activation. Nature. 2003;423(6937):337-342.

30. Manolagas SC, Jilka RL. Bone marrow, cytokines, and bone remodeling. Emerging insights into the pathophysiology of osteoporosis. $N$ Engl J Med. 1995;332(5):305-311

31. Vgontzas AN, Papanicolaou DA, Bixler EO, et al. Sleep apnea and daytime sleepiness and fatigue: relation to visceral obesity, insulin resistance, and hypercytokinemia. J Clin Endocrinol Metab. 2000;85(3):1151-1158.

32. Dyugovskaya L, Polyakov A, Lavie P, Lavie L. Delayed neutrophil apoptosis in patients with sleep apnea. Am J Respir Crit Care Med. 2008;177(5):544-554.

33. Bozec A, Bakiri L, Hoebertz A, et al. Osteoclast size is controlled by Fra-2 through LIF/LIF-receptor signalling and hypoxia. Nature. 2008;454(7201):221-225

34. Chilibeck PD, Sale DG, Webber CE. Exercise and bone mineral density. Sports Med. 1995;19(2):103-122.

35. Vuori I. Peak bone mass and physical activity: a short review. Nutr Rev. 1996;54(4 Pt 2):S11-S14.

36. Wallace BA, Cumming RG. Systematic review of randomized trials of the effect of exercise on bone mass in pre- and postmenopausal women. Calcif Tissue Int. 2000;67(1):10-18.

37. de Kam D, Smulders E, Weerdesteyn V, Smits-Engelsman BC. Exercise interventions to reduce fall-related fractures and their risk factors in individuals with low bone density: a systematic review of randomized controlled trials. Osteoporos Int. 2009;20(12):2111-2125.

38. Li WC, Chen YC, Yang RS, Tsauo JY. Effects of exercise programmes on quality of life in osteoporotic and osteopenic postmenopausal women: a systematic review and meta-analysis. Clin Rehabil. 2009;23(10):888-896.

39. Bradley TD, Brown IG, Grossman RF, et al. Pharyngeal size in snorers, nonsnorers, and patients with obstructive sleep apnea. $N$ Engl J Med. 1986;315(21):1327-1331.

40. Squier SB, Patil SP, Schneider H, Kirkness JP, Smith PL, Schwartz AR. Effect of end-expiratory lung volume on upper airway collapsibility in sleeping men and women. J Appl Physiol (1985). 2010;109(4):977-985.

41. Heinzer RC, Stanchina ML, Malhotra A, et al. Effect of increased lung volume on sleep disordered breathing in patients with sleep apnoea. Thorax. 2006;61(5):435-439.

42. Watanabe R, Tanaka T, Aita K, et al. Osteoporosis is highly prevalent in Japanese males with chronic obstructive pulmonary disease and is associated with deteriorated pulmonary function. J Bone Miner Metab. Epub July 5, 2014.

43. Masala S, Magrini A, Taglieri A, et al. Chronic obstructive pulmonary disease (COPD) patients with osteoporotic vertebral compression fractures (OVCFs): improvement of pulmonary function after percutaneous vertebroplasty (VTP). Eur Radiol. 2014;24(7):1577-1585.

44. Chetta A, Pisi G, Aiello M, Tzani P, Olivieri D. The walking capacity assessment in the respiratory patient. Respiration. 2009;77(4): 361-367. 
International Journal of COPD

\section{Publish your work in this journal}

The International Journal of COPD is an international, peer-reviewed journal of therapeutics and pharmacology focusing on concise rapid reporting of clinical studies and reviews in COPD. Special focus is given to the pathophysiological processes underlying the disease, intervention programs, patient focused education, and self management protocols.

This journal is indexed on PubMed Central, MedLine and CAS. The manuscript management system is completely online and includes a very quick and fair peer-review system, which is all easy to use. Visit $\mathrm{http}: / /$ www.dovepress.com/testimonials.php to read real quotes from published authors.

Submit your manuscript here: http://www.dovepress.com/international-journal-of-copd-journal 